\title{
Analisis Video Likes to Video Views Ratio Tiktok Pada Top 5 Brand Sepatu Terkenal Dunia
}

\author{
Anak Agung Adi Sastrawan
}

Agungsastrawan19@gmail.com

\begin{abstract}
TikTok is a social media application launched by a Chinese company. TikTok allows users to create 15 -second videos accompanied by music, filters, and several other creative features. In Indonesia, there are 30.7 million active users, making Indonesia the country with the largest TikTok users in the world. The large number of active TikTok users in Indonesia can certainly provide an opportunity for brands to make the TikTok platform a social media marketing platform. There are 5 world famous shoe brands that use TikTok as a marketing platform, namely: New Balance, Vans, Converse, Adidas, Nike. The purpose of this study is to calculate the credibility of the TikTok account performance of the Top 5 Smartphone Vendors in Indonesia. The method used for this research is quantitative exploratory method. The results of this study indicate that the smartphone vendor Oppo Indonesia is ranked first and has good account performance credibility.
\end{abstract}

\begin{abstract}
ABSTRAK
TikTok merupakan aplikasi sosial media yang diluncurkan oleh perusahaan asal Tiongkok. TikTok memungkinkan penggunanya membuat video berdurasi 15 detik yang disertai dengan musik, filter, dan beberapa fitur kreatif lainnya. Di Indonesia terdapat 30,7 juta pengguna yang aktif sehingga menjadikan Indonesia sebagai negara dengan pengguna TikTok terbesar di dunia. Maraknya jumlah pengguna TikTok yang aktif di Indonesia tentu dapat memberikan peluang bagi brand untuk menjadikan platform TikTok sebagai platform social media marketing. Adapun 5 brand sepatu terkenal didunia yang memanfaatkan TikTok sebagai platform marketing, yaitu : New Balance, Vans, Converse, Adidas, Nike. Tujuan dari penelitian ini yaitu untuk menghitung kredibilitas dari performa akun TikTok Top 5 Vendor Smartphone di Indonesia. Metode yang digunakan untuk penelitian ini yaitu metode eksploratif kuantitatif. Hasil dari penelitian ini menunjukan bahwa vendor smartphone Oppo Indonesia mendapatkan peringkat pertama dan memiliki kredibilitas performa akun yang baik.
\end{abstract}

Keyword : Credibility Account TikTok ; Social Media Marketing ; Social Media TikTok ; Video Likes to Video Views Ratio ; World Famous Shoe Brands. 


\section{PENDAHULUAN}

Perkembangan Teknologi Informasi dan Komunikasi yang sangat cepat memberikan pengaruh yang sangat besar pada kehidupan manusia, berbagai macam kemudahan ditawarkan dalam perkembangan teknologi saat ini, salah satunya adalah dalam hal berinteraksi sosial yang dulu dilakukan dengan cara datang langsung ketempat orang yang akan dituju tetapi dengan perkembangan teknologi sekarang ini interaksi sosial dapat dilakukan pada dunia maya. Banyak media yang dapat digunakan untuk melakukan interaksi sosial bahkan juga dapat melakukan kegiatan usaha pada media sosial tersebut contohnya saja media sosial tiktok,

Tik Tok merupakan aplikasi media sosial terbaru yang memungkinkan pengguna untuk membuat dan berbagai video menarik, berinteraksi dikolom komentar maupun chat pribadi. Aplikasi ini menghadirkan special effects yang menarik dan mudah digunakan. Sehingga semua orang bisa menciptakan sebuah video yang keren, hal ini yang menjadikan Tik-Tok sebagai aplikasi dengan banyak pengguna.Terbukti dengan Rating yang didapatkan dari playstore aplikasi tersebut 4,6 dari 5 bintang terbaik dan sekitar 27,827 pengguna diseluruh dunia dibandingkan aplikasi sejenis yaitu Musicaly dengan rating 3,5 dari 5 bintang terbaik kemudian 4,100 pengguna. (Deriyanto \& Qorib, 2019)

Dengan banyaknya pengguna Media Sosial TikTok membuka peluang bagi banyak orang untuk melakukan promosi untuk usaha dan jasa, bahkan 5 Brand Sepatu Terkenal Didunia seperti: VANS, Adidas, Nike, New Balance dan Converse (Begini Sejarah 5 Brand Sepatu Terkenal Dunia, n.d.) tidak ketinggalan untuk menggunakan TikTok sebagai media marketing yang sangat menjanjikan dan tidak memerlukan biaya yang banyak.

Penelitian ini menggunakan metode eksploratif kuantitatif, dan akan menghitung menggunakan rasio-rasio yang ada pada TikTok. Pada penelitian (Permana \& Meinarni, 2021) menjelaskan bahwa terdapat 17 rasio yang ada pada sosial media TikTok dan relevan digunakan sebagai media ukur kredibilitas akun yang ada. Penelitian ini hanya berfokus untuk menghitung kredibilitas Video Likes to Video Views Ratio pada 5 Brand Sepatu Terkenal Didunia, adapun 5 Brand Sepatu Terkenal Didunia yaitu: VANS, Adidas, Nike, New Balance dan Converse (Begini Sejarah 5 Brand Sepatu Terkenal Dunia, n.d.).Tujuan dari penelitian ini adalah mengetahui kredibilitas performa dari akun TikTok 5 Brand Sepatu Terkenal Didunia menggunakan Video Likes to Video Views Ratio.

\section{TINJAUAN PUSTAKA}

Perkembangan teknologi yang sangat pesat saat ini terjadi menghasilkan berbagai macam aplikasi - aplikasi media sosial yang banyak diminati oleh berbagai kalangan karena fungsi dan pemakaiannya yang sederhana dan juga dapat memberikan informasi yang sangat cepat sehingga keterbatasan jarak tidak lagi menjadi masalah dalam penyebaran informasi dan hiburan

TikTok diciptakan oleh Zhang Yiming yang juga merupakan pendiri Toutiao. Dengan aplikasi ini, pengguna bisa membuat video musik mereka sendiri dan bebas mengekspresikan diri. TikTok dikembangkan oleh Beijing ByteDance Technology dan berasal dari Tiongkok. Dia bisa diunduh melalui Play Store untuk pengguna android dan 
App Store untuk pengguna iOS. Anda juga bisa membukanya melalui PC. TikTok diciptakan oleh Zhang Yiming yang juga merupakan pendiri Toutiao. Dengan aplikasi ini, pengguna bisa membuat video musik mereka sendiri dan bebas mengekspresikan diri.(Tik Tok Adalah (Pengertian), Asal, Manfaat, Efek Negatifnya | Social Media Marketing Specialist, n.d.)

Tiktok juga dilengkapi dengan Artificial Intelligence yang dapat mengatur algoritma sehingga rekomendasi yang diberikan oleh aplikasi tersebut sesuai dengan keinginan penggunanya entah itu rekomendasi musik atau lagu maupun feeds atau rekomendasi tontonan. Selain itu perusahaan juga berusaha meningkatkan konsumer melalui kompetisi offline misalkan di tahun 2017 yang bernama National Youth Talent Competition dimana kompetisi ini merupakan kerja sama dengan media Jundi Brothers. Hal ini tentunya diikuti dengan penyebaran aplikasi ke luar negeri yang memfokuskan pada wilayah Asia Tenggara, Jepang, dan Korea Selatan sesuai dengan target pemasaran. (Antoni, 2018)

Aplikasi Tiktok semakin mengembangkan layanannya terhadap pengguna.

Selain bisa menghasilkan uang tiap hari, Tikto juga menjadi ecommers untuk belanja online. TikTok secara resmi menghadirkan fitur belanja online di Indonesia yang diberi nama TikTok Shop. Fitur ini merupakan sebuah layanan inovatif e-commerce yang dapat menjangkau para penjual, pembeli, dan kreator untuk menyediakan pengalaman berbelanja langsung dari TikTok.(Perkembangan Tiktok Terkini Tetap Hasilkan Uang Tiap Hari Dan Bisa Belanja Online - Tribunpontianak.Co.Id, n.d.)

Dengan adanya perkembangan fitur promosi dan belanja online membuat tiktok menjadi media yang cukup digemari untuk para brand besar untuk melakukan marketing pada aplikasi tiktok yang menjanjikan, sehingga kedepannya perkembangan tiktok masih sangat panjang.

\section{METODE PENELITIAN}

Dalam penelitian ini menggunakan metode penelitian kuantitatif dimana data yang didapatkan berupa angka dan bilangan (Abdullah, 2015)

Tujuan dari penelitian ini yaitu mengetahui nilai performed dari akun TikTok 5 Brand Sepatu Terkenal Dunia. Ada beberapa langkah yang harus dilakukan dalam penelitian ini, sehingga mampu menemukan peringkat pertama akun TikTok Brand Sepatu Terkenal Dunia yang memiliki performa terbaik. Langkah-langkah yang dilakukan pada penelitian ini, diantaranya yaitu :

\section{Melakukan Eksplorasi Pada Website Untuk Menentukan Objek yang Akan Dianalisa.}

Eksplorasi ini dilakukan pada beberapa halaman website yang menyediakan informasi mengenai objek yang akan di teliti. Setelah diapatkan hasil eksploari selanjutnya adalah memastikan bahwa 5 Brand Sepatu Terkenal Dunia memiliki akun media sosial tiktok

\section{Menghitung Nilai Rata-Rata Variable Dari Top 5 Vendor Smartphone di Indonesia.}


Selanjutnya adalah menghitung variable video like to video views. Variabel adalah konsep yang mengandung variasi nilai (Nasution, 2017). Untuk menghitung nilai ratarata dari variabel video comments dan variabel video views yaitu dengan cara mengambil minimal 10 postingan kemudian di hitung sehingga menemukan nilai ratarata dari masing-masing variabel.

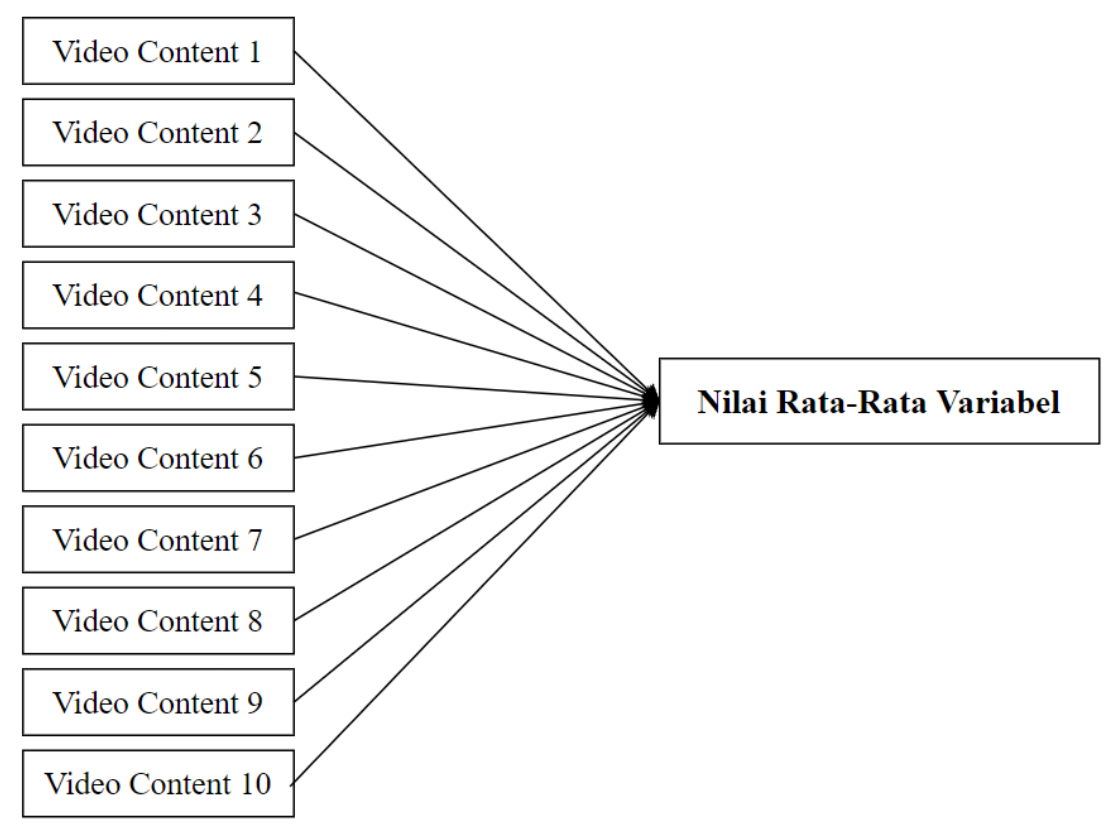

Gambar 1. Analisa Nilai Rata-Rata Variabel.

\section{Menghitung Nilai Kredibilitas Rasio}

Untuk menghitung nilai kredibilitas dari video likes to video views ratio, peneliti menggunakan cara membagi nilai variabel pertama dengan nilai variabel kedua. Jika video likes memiliki nilai 100 dan video views memiliki nilai 300, maka cara menghitungnya yaitu $100: 300=0,3$. Dengan begitu nilai dari video likes to video views ratio adalah 0,3 .

\section{Menentukan Peringkat Pada Akun TikTok}

Langkah terakhir yang dilakukan pada penelitian ini yaitu menentukan peringkat pada masing-masing rasio yang ada. Pada penentuan peringkat perlu melihat karakteristik dari rasio yang di teliti. Jika karakteristik rasio merupakan rendah, maka objek yang memiliki nilai terendah akan mendapatkan angka 5 dan objek yang memiliki nilai tertinggi akan mendapatkan angka 1. Namun jika rasio memiliki karakteritik tinggi maka objek yang mendapatkan nilai tinggi akan mendapatkan angka 5 dan objek yang mendapatkan nilai terendah akan mendapatkan angka 1. Setelah mendapatkan hasil kredibilitas ratio maka dapat disimpulkan objek yang mana mendapatkan peringkat 1 sampai dengan peringkat 5 . 


\section{HASIL DAN PEMBASAN}

Akun TikTok dari Top 5 Bran Sepatu Terkenal Dunia, diantaranya :

\section{New Balance}

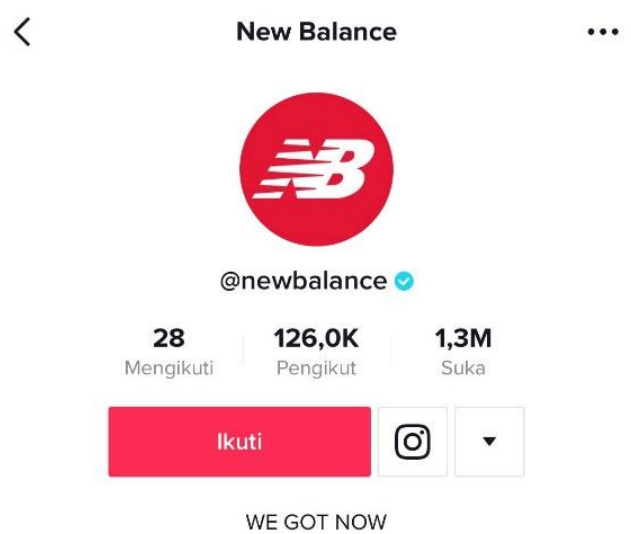

Gambar 1. Akun New Balance

Sumber : https://www.tiktok.com/@newbalance (akses pada 06-10-2021)

2. Vans

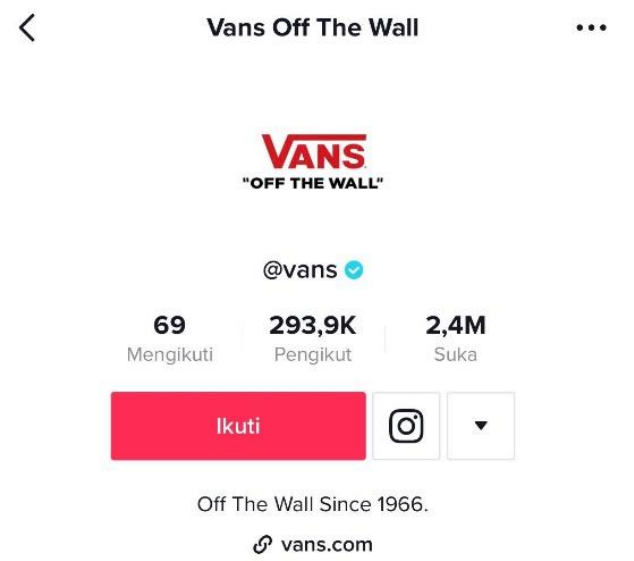

Gambar 2. Akun Vans

Sumber : https://www.tiktok.com/@vans (akses pada 06-10-2021) 


\section{Converse}

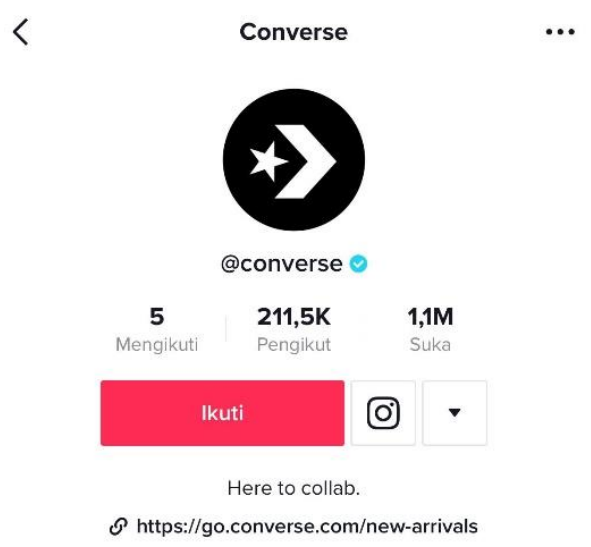

Gambar 3. Akun Converse

Sumber : https://www.tiktok.com/@converse (akses pada 06-10-2021)

\section{Adidas}

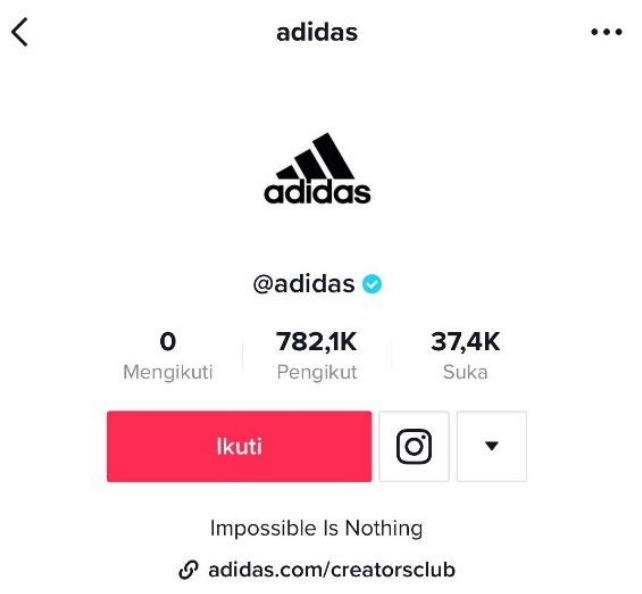

Gambar 4. Akun Adidas

Sumber : https://www.tiktok.com/@adidas (akses pada 06-10-2021) 


\section{Nike}

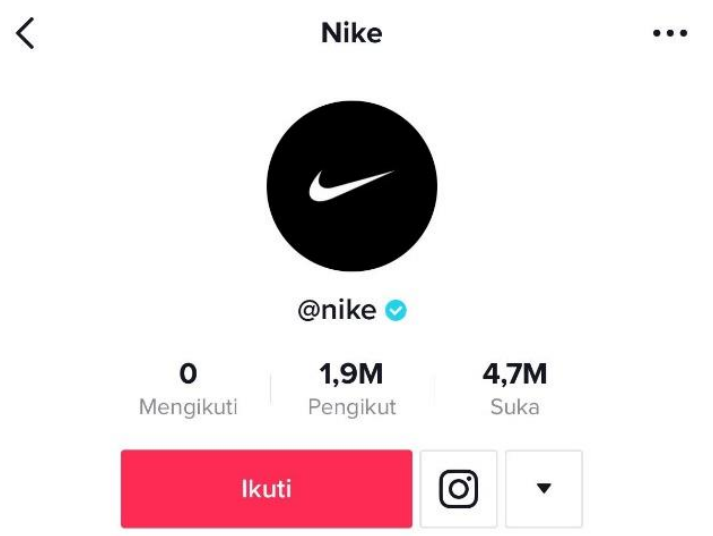

Gambar 4. Akun Adidas

Sumber : https://www.tiktok.com/@nike (akses pada 06-10-2021)

Dari kelima akun TikTok Top 5 Brand Sepatu Terkenal Dunia, peneliti menemukan nilai dari masingmasing variabel yang ada untuk menghitung rasio Video Likes to Video Views dari setiap akun. Pada akun TikTok terdapat 7 variabel, diantaranya yaitu :

1. Likes

2. Followers

3. Following

4. Video Likes

5. Video Comments

6. Video Share

7. Video Views

Dari ketujuh variabel tersebut peneliti hanya fokus untuk menemukan hasil dari 2 variabel, yaitu :

1. Video Likes

2. Video Views

Dari kedua variabel tersebut kemudian dianalisa sehingga menemukan nilai rata-rata dari variabel video Likes dan variabel video views. Untuk menghitung nilai rata-rata dari variabel video Likes dan variabel video views yaitu dengan cara mengambil minimal 10 postingan kemudian di hitung sehingga 
menemukan nilai rata-rata dari masing-masing variabel. Berikut merupakan tabel nilai rata-rata dari masing-masing Brand Sepatu Terkenal Dunia, yaitu :

Tabel 1. Analisa Nilai Rata-Rata Nilai Variabel Video Likes dan Video Views Akun

TikTok New Balance

\begin{tabular}{|c|c|c|}
\hline No & $\begin{array}{l}\text { Video } \\
\text { Like } \\
\end{array}$ & Video Views \\
\hline 1 & 29,300 & $3,800,000$ \\
\hline 2 & 100,000 & $4,500,000$ \\
\hline 3 & 120,000 & $4,800,000$ \\
\hline 4 & 68,000 & $2,800,000$ \\
\hline 5 & 38,000 & 530,000 \\
\hline 6 & 38,000 & $2,700,000$ \\
\hline 7 & 64,800 & $3,100,000$ \\
\hline 8 & 204,000 & $4,600,000$ \\
\hline 9 & 349,900 & $27,100,000$ \\
\hline 10 & 307,700 & $14,700,000$ \\
\hline Total & 130,720 & $6,863,000$ \\
\hline
\end{tabular}

Tabel 2. Analisa Nilai Rata-Rata Nilai Variabel Video Likes dan Video Views Akun

TikTok Vans

\begin{tabular}{|c|c|c|}
\hline No & $\begin{array}{l}\text { Video } \\
\text { Like } \\
\end{array}$ & Video Views \\
\hline 1 & 644 & 5,961 \\
\hline 2 & 599 & 5,679 \\
\hline 3 & 551 & 6,537 \\
\hline 4 & 3,362 & 22,300 \\
\hline 5 & 450 & 7,784 \\
\hline 6 & 712 & 8,785 \\
\hline 7 & 485 & 7,296 \\
\hline 8 & 1,505 & 14,200 \\
\hline 9 & 3,335 & 23,900 \\
\hline 10 & 2,156 & 17,500 \\
\hline Total & 1,380 & 11,994 \\
\hline
\end{tabular}


Tabel 3. Analisa Nilai Rata-Rata Nilai Variabel Video Likes dan Video Views Akun TikTok Converse

\begin{tabular}{|c|c|c|}
\hline No & $\begin{array}{c}\text { Video } \\
\text { Like } \\
\end{array}$ & Video Views \\
\hline 1 & 803 & 7,106 \\
\hline 2 & 7,591 & 31,200 \\
\hline 3 & 755 & 9,343 \\
\hline 4 & 654 & 9,271 \\
\hline 5 & 2,012 & 14,300 \\
\hline 6 & 2,665 & 17,800 \\
\hline 7 & 1,013 & 14,100 \\
\hline 8 & 1,328 & 17,300 \\
\hline 9 & 1,909 & 17,500 \\
\hline 10 & 1,901 & 18,100 \\
\hline Total & 2,063 & 15,602 \\
\hline
\end{tabular}

Tabel 4. Analisa Nilai Rata-Rata Nilai Variabel Video Likes dan Video Views Akun TikTok Adidas

\begin{tabular}{|c|c|c|}
\hline No & $\begin{array}{c}\text { Video } \\
\text { Like }\end{array}$ & Video Views \\
\hline 1 & 6,405 & 49,200 \\
\hline 2 & 3,008 & 41,400 \\
\hline 3 & 7,931 & 116,700 \\
\hline 4 & 16,300 & 219,900 \\
\hline 5 & & \\
\hline 6 & & \\
\hline 7 & & \\
\hline 8 & & \\
\hline 9 & & \\
\hline 10 & $\mathbf{8 , 4 1 1}$ & $\mathbf{1 0 6 , 8 0 0}$ \\
\hline Total & & \\
\hline \multicolumn{3}{|c|}{ Sumber : Pengolah Data Excel }
\end{tabular}


Tabel 5. Analisa Nilai Rata-Rata Nilai Variabel Video Likes dan Video Views Akun

TikTok Nike

\begin{tabular}{|c|c|c|}
\hline No & $\begin{array}{l}\text { Video } \\
\text { Like }\end{array}$ & Video Views \\
\hline 1 & 1,206 & 16,900 \\
\hline 2 & 1,664 & 24,800 \\
\hline 3 & 1,229 & 21,600 \\
\hline 4 & 2,707 & 31,800 \\
\hline 5 & 2,863 & 34,700 \\
\hline 6 & 1,787 & 27,600 \\
\hline 7 & 1,917 & 29,400 \\
\hline 8 & 2,322 & 34,800 \\
\hline 9 & 6,009 & 66,000 \\
\hline 10 & 2,075 & 32,200 \\
\hline Total & 2,378 & 31,980 \\
\hline
\end{tabular}

Sumber : Pengolah Data Excel

Setelah menghitung nilai rata-rata tersebut, maka akan menemukan hasil akhir nilai rata-rata dari variabel video Likes dan Video Views

Tabel 6. Nilai Variabel Pada Akun TikTok Top 5 Brand Sepatu Dunia

\begin{tabular}{|l|c|c|c|c|l|}
\hline Variable & $\begin{array}{l}\text { NEW } \\
\text { BALANCE }\end{array}$ & VANS & CONVERSE & ADIDAS & NIKE \\
\hline Video Likes & 1380 & 2063 & 2063 & 8411 & 2378 \\
\hline Video Views & 6863000 & 11994 & 15602 & 106800 & 31980 \\
\hline
\end{tabular}


Tabel 7. Hasil Perhitungan Rasio Akun TikTok

\begin{tabular}{|c|c|c|c|c|c|c|}
\hline $\begin{array}{l}\mathrm{N} \\
\mathrm{O}\end{array}$ & RATIO & $\begin{array}{l}\text { NEW } \\
\text { BALANCE }\end{array}$ & VANS & CONVERSE & ADIDAS & NIKE \\
\hline 1 & $\begin{array}{l}\text { Video Likes to Video } \\
\text { Views } \\
\text { Ratio }\end{array}$ & 0.01904706 & 0.11504727 & 0.13223305 & 0.07875468 & 0.07435585 \\
\hline
\end{tabular}

Sumber : Pengolah Data Excel

Video Likes to Video Views Ratio memiliki karakteristik yang tinggi, artinya semakin tinggi nilai yang dihasilkan maka semakin baik kredibilitas dari performa akun tersebut. Untuk memberikan peringkat pada masing-masing Brand Sepatu Terkenal Dunia, peneliti memberikan angka 5 kepada Brand yang mendapatkan nilai tertinggi dan angka 1 untuk Brand yang mendapatkan nilai terendah. Berikut merupakan tabel urutan nilai yang dihasilkan oleh masing-masing Brand Sepatu Terkenal Dunia.

Tabel 8. Nilai Rasio Akun TikTok Top 5 Vendor Smartphone di Indonesia Q1-2021

\begin{tabular}{|l|c|c|c|c|c|}
\hline \multirow{2}{*}{ RATIO } & \multicolumn{3}{|c|}{ NILAI } \\
\cline { 2 - 6 } & $\begin{array}{l}\text { NEW } \\
\text { BALANCE }\end{array}$ & VANS & CONVERSE & ADIDAS & NIKE \\
\hline $\begin{array}{l}\text { Video Comments to } \\
\text { Video Views Ratio }\end{array}$ & 3 & 2 & 4 & 5 & 1 \\
\hline
\end{tabular}

Sumber : Pengolah Data Excel

Dari Tabel Nilai Rasio Akun TikTok Top 5 Brand Sepatu Terkenal Dunia dapat simpulkan bahwa ADIDAS mendapatkan nilai tertinggi untuk rasio Video Likes to Video Views. Sedangkan akun TikTok NIKE mendapatkan nilai terendah untuk rasio ini. Jadi, pada penelitian ini ADIDAS memiliki kredibilitas performa yang lebih baik dibandingkan dengan Brand yang lainnya. 


\section{KESIMPULAN}

Tujuan dari penelitian ini adalah mengetahui kredibilitas performa dari akun TikTok Top 5 Brand Sepatu Terkenal Dunia menggunakan Video Likes to Video Views Ratio. Top 5 Brand Sepatu Terkenal Dunia tersebut diantaranya : NEW BALANCE, VANS, CONVERSE, ADIDAS, NIKE. Dari kelima Brand Sepatu Terkenal Dunia tersebut dapat disimpulkan bahwa :

1. Peringkat pertama diraih oleh ADIDAS dengan nilai tertinggi yaitu 0.07875468

2. Peringkat kedua diraih oleh CONVERSE dengan nilai 0.13223305

3. Peringkat ketiga diraih oleh NEW BALANCE dengan nilai 0.01904706

4. Peringkat keempat diraih oleh VANS dengan nilai 0.11504727

5. Peringkat kelima diraih oleh NIKE dengan nilai terendah yaitu 0.07435585 